\title{
A Model for Incorporated Measurement of Sustainable Development Comprising Remote Sensing Data and Using the Concept of Biodiversity
}

\author{
Azniv Petrosyan \\ Laboratory of Remote Sensing, School of Rural and Surveying Engineering \\ National Technical University of Athens, Heroon Polytechnion 9, 15780 Athens, Greece \\ E-mail: pet_azniv@yahoo.com
}

\begin{abstract}
The central point of the paper is on concern of how to utilize indicators to observe sustainable development in an applicable and valuable way. The aim of the work was to propose a model for achieving a composite sustainable development index using the concept of Biodiversity in order to track incorporated information on social, economic and environmental dimension of the municipality with time periods, according to:

1) Social (Population);

2) Economic (Agriculture, Tourism, Agricultural Goods and Industry);

3) Environmental (output of remote sensing data using Fragstat software).

An attractive approach is suggested for the environmental dimension. The calculated metrics become an input to the model like Environmental Indicators. In addition, the concepts of Biodiversity are kept for Environmental Indicators in the following way: Ecosystem $=$ Landscape Level and Species $=$ Class Level. Finally, the results, discussions and conclusions are provided for each existing theme, each dimension and CSDI.
\end{abstract}

Keywords: Sustainable development, Sustainability assessment, Sustainability indicators, Composite index, Remote sensing metrics, Multi-attribute decision-making, Biodiversity

\section{Introduction}

Today's decision-makers are living in a weird contradiction: there is both too much and too little information. In other words, the enormous amounts of information accessible are out of the needs of the decision-makers. Both insufficient and excessive data can be problems in selecting indicators (Finco and Nijkamp, 2001). In any country, identifying the indicators according to the district circumstances would make them even more cooperative for political decision-making (Spangenberg and Lorek, 2002). Varma et al. (2000); Bell and Morse (2004) and Simianer (2005) highlighted that decision-making involves three following sub-goals:

a definition of sustainability that recognizes its ecological, economic and social underpinning, i.e what is the objective?

finding ways to measure sustainability with due regard to its spatial and temporal dimensions, i.e. what is the decision space?

operationalising sustainability in terms of identifying strategies to improve management, wherever needed, i.e. how can we decide?

Gallopin (1997) and Rigby et al. (2001) survey a wide range of literature and reports that in different sources an environmental indicator has been identified as "a variable...a parameter...a measure...a statistical measure...a proxy...a value...a meter or measuring instrument...a fraction...an index...something... a piece of information... a single quantity... an empirical model... a sign". Indicators are pieces of information, which simplify complex phenomena and highlight the trends of system functioning, through summarizing or typifying the characteristics of particular systems (Pagina, 2000).

A good indicator should satisfy a number of criteria Tate (2002). Further, what are the criteria of sustainability, or the critical thresholds, that could be applied across these dimensions to facilitate judgments as to whether development is sustainable or not (Ekins et al., 2008). De Kruijf and Van Vuuren (1998); Ravetz (2000); Spangenberg et al. (2002); The Energy \& Biodiversity Initiative (2002); Yuan and James (2002); Ledoux et al. (2005) have developed a number of additional criteria to determine the quality of indicators selected or proposed. Indicators, according to these criteria should furthermore be:

independent, i.e. each indicator must be meaningful in itself;

indicative, i.e. an indicator must be truly representative of the phenomenon it is intended to characterise;

general, i.e. not dependent on a specific situation, culture or society, but be meaningful for different perceptions of reality, whether dominant for society or not;

robust, i.e. directionally safe with no significant changes in case of minor changes in the methodology or improvements in the data base; 
sensitive, i.e. they have to react early and sensibly to changes in what they are monitoring, in order to permit monitoring of trends or the successes of policies.

Pressure-State-Response (PSR) methodology was developed by the OECD, for the categorization of environmental indicators, and is based on the "stress-response" model (OECD, 1993). Since the layout echoes the well-known pressure-state-response framework, the structure might also aid the identification of causal links between metrics (Keirstead and Leach, 2008). The PSR methodology does not try to determine the nature or to shape interactions between human activities and the situation of the environment but tried to express how the human activities exert pressures in the environment that can involve changes. The society then reacts through the changes with environmental and economical policies and programs, which intend to prevent or to decrease pressures. The methodology's components according to Patlitzianas et al. (2008) and Buchs (2003) are described as follows:

Pressure: It describes direct and indirect pressures of human activities that are applied in the environment. (What is causing the environmental conditions to change?)

State: It concerns the environmental conditions from the above-mentioned pressures. (What are the effects on the environment?)

Response: It describes the actions taken to prevent or to decrease the environmental repercussions and to maintain the natural resources. (What actions are being taken in public and private sectors to respond to changes in the state of the environment?).

Lyytimaki and Rosenstrom (2008) presented a holistic illustration of sustainable development framework (Figure 1). Levett (1998) discuss the (proposed) russian dolls model of sustainability (Figure 2). Figure 3 also shows the different states of sustainability that could exist for any development. Sustainability is usually discussed as a state or, better, a development in which three kinds of interests are met simultaneously: (1) the interest of the present generation to generally improve their actual living conditions (i.e. economic sustainability), (2) the search for an equalization of the living conditions between rich and poor (i.e. social sustainability), and (3) the interest in an intact natural environment that is capable of supporting the needs of future generations (i.e. ecological sustainability) (Sartorius, 2006; Ledoux et al., 2005). First order state reflects only economic, social, or environmental issues separately. Any project thus executed can only attain a single state sustainable status. Traditionally, projects in the construction sector have often explored such a single state sustainability within the economic dimension. The second order state describes a partial overlap between two dimensions, such as economic and environmental optimisation at the expense of the social dimension. Its generic form is the optimisation of any two dimensions at the expense of the third dimension. The third order of sustainability refers to an optimisation of all three dimensions, and is a state that is rarely attained in most urban development projects in isolation. The ability to establish optimisation of the third order relies on the awareness of the issues and dominant requirements that is each of the principal dimensions within a generic as well as a specific spatial context. The social dimension presents the aspect of sustainability that is most difficult to define. This is because of a greater proportion of subjective factors that is reflected as dominant requirements for consideration. As such, defining generic social factors that would require attention in the assessment of sustainability should present an opportunity for conducting a more systematic appraisal of the issues that would need to be addressed (Edum-Fotwe and Price, 2009).

The European Union Strategy for Sustainable Development focuses on six themes, which are enhanced, by four other themes derived from further discussion on sustainability by the EU, UN, etc. (EUROSTAT, 2007). In this paper, approximately 350 indicators that are classified into three dimensions, i.e. social, economic and environmental dimensions. Each dimension is sub- classified into 6 themes (Table 1). However, according to the availability of statistical data on the municipality of Neas Makris, the existing themes are as follows:

1) Social dimension is based on Population theme;

2) Economic dimension relies on Agriculture, Tourism, Agricultural Goods and Industry themes;

3) Environmental dimension represents the output of remote sensing data using Fragstat software.

An attractive approach is suggested for the environmental dimension. The calculated metrics become an input to the model like Environmental Indicators. In addition, the concept of Biodiversity are kept for Environmental Indicators in the following way: Ecosystem = Landscape Level and Species = Class Level. Finally, the results, discussions and conclusions are provided for each existing theme, each dimension and CSDI.

\section{Materials and Methods}

\subsection{Study Area}

Neas Makris (Figure 4), also Neas Makris is a town located in the northeastern part of Attica and the peninsula. The area was once known as Plesti, but following the 1922 Greek military disaster in Asia Minor and the subsequent repatriation of Greeks from the town of Makris, it was renamed Neas Makris (New Makri). Until the 1970s, most of the population was rural. As housing developments came to the area, the population boomed and filled into the settlements. Housing developments continue to this day. Due to statistics taken from national 
statistical service of Greece (2001) and from Wikipedia (free encyclopedia), the population of Neas Makris is 14,809 , the area is $36.662 \mathrm{~km}^{2}$ and the density is $404 / \mathrm{km}^{2}$.

According to (Kosioni-Koen and Papastergiou-Mitsopoulou, 2004) the development model of municipality for the year 2011 will be the following:

Municipality of Neas Makris is planning to have population of 47000 with 21000 (44\%) private and 26000 (56\%) holidaymakers;

Protected, given ranks and stayed with development the following:

Penteliko with the limits of protection which was established in the year of 1988;

Forested areas;

Coastlines;

Remote zones;

Archeological area for protection Briksezas and small archeological area in the center. Recently it has been organized an ongoing Archeological Museum of Neas Makris;

Metavizantina Monuments of Monon Agias Paraskevis and Agias Ioannis Theologoy and chapel of Agioy Petrou.

Given for the ribbon development;

Conservation and support of highlighted characters of the center of Neas Makris and developing areas of recreation and cultural accoutrements according to the followings:

Creation of Multifunctional Park with the cultural-athletic-educational use on the full space of old American Base, Outdoors Theaters of old Tamari and Cultural Center;

Development of zones for tourists and pleasures along the seaside;

Functionality of camps in Agia Andrea;

Creation of marinas for tourists;

Extension and accoutrements of the center of town;

New big roads (Athens Roads and Stavro-Rafinas highways).

Organization of municipality;

Forecasting of the needs for all kinds of social services;

Works on the drainage systems;

Topics of Traffics;

Creation of the nets for general collection of roads;

Creation of nets for sidewalks and bicycling.

\subsection{Data Sets}

\subsubsection{Existing Remote Sensing Data}

There are five (5) Landsat Thematic Mapper and two (2) Landsat Enhanced Thematic Mapper Plus (ETM+) satellite images. The whole information for satellite images is shown in Table 3.1.

The detailed work of all images has been performed initially for all images. However, only highlighted images, i.e. Landsat TM (23/10/1984); Landsat TM (04/07/1990); Landsat ETM+ (14/08/2002) will be used for the Statistical Calculations.

\subsubsection{Existing Statistical Data}

Existing Statistical Data are presented in the Table 3. Due to hugeness of the current thesis only the chosen dates will be used (see Table 4).

\subsection{Methodology}

\subsubsection{Background}

To create a combined metric, footprint values (first metric) and sustainability indices (second metric) were aggregated to generate a Combined Sustainable Development Index (CSDI) for settlements: to achieve this, footprint values were transformed to create an index additional to environmental, quality of life, socio-economic and transport indices and the five values were aggregated, an aggregation method also adopted by Wilson et al. (2007). This was undertaken to include all available data, but resulted in double counting of some environmental attributes, which was accepted on the assumption that social and economic sustainability are ultimately dependent on environmental quality. To allow comparison amongst settlements with differing population sizes, all sustainability values were calculated on a per capita basis (O’Regan et al., 2009). 
Despite of Combined Sustainable Development Index (CSDI), Krajnc and Glavic (2005a) collected and developed a standardized set of sustainability indicators for companies covering all main aspects of sustainable development. A composite sustainable development index (CSDI) in order to track integrated information on economic, environmental, and social performance of the company with time. Normalized indicators were associated into three sustainability subindices and finally composed into an overall indicator of a company performance. This was applied by determining the impact of individual indicator to the overall sustainability of a company using the concept of analytic hierarchy process (Singh et al., 2009). Blanc et al. (2008) points to the existence of four steps in constructing a composite index:

the selection,

the scaling,

the weighting and

the aggregation of the variables.

In all indicator frameworks no attempt was made to create aggregate measure for easy comparison. In recent years, international research has focused on the development of composite indicators mostly for cross-national comparisons of economic, social, environmental and/or sustainable progress of nations in a quantitative fashion. Such indicators have been applied in a wide variety of application fields such as:

- Society: human development index (UNDP, 1990-2003), overall health system attainment (Murray et al., $2001)$

- Economy: internal market index (JRC, 2002), composite leading indicators (OECD, 2002), index of sustainable and economic welfare (Daly and Cobb, 1989);

- Environment: pilot environmental performance index (WEF, 2002), index of environmental friendliness (Statistics Finland, 2003), eco-indicator 99 (Pre Consultants, 2001).

Despite the indices developed, there is still no useful method for integrated sustainability assessment. To meet the challenges of sustainability, an approach for integrated assessment is required to provide a good guidance for decision-making. It has been foreseeable that aggregation of indicators to sustainability indices could provide a chance for new policy guiding instruments and better integration of decision-making, as well as public participation in sustainability discussion. Although the common principle to aggregate indicators for assessment has gained acceptance, it has also become evident that methods for the aggregation of indicators are either not sufficiently well established yet, or are under development, or are not available with respect to all the sustainability aspects. As the credibility of aggregation methodologies is of crucial importance for the quality of new information categories, more research is needed on the aggregation methodologies and on the relevance of basic data for comprehensive assessments (Statistics Finland, 2003).

The paper of Krajnc and Glavic (2005a) presents a designing of a composite sustainable development index (CSDI) that would assess performance as a function of time. The focus of the paper is a consideration how to integrate indicators in order to determine SD in a relevant and useful manner for decision-making. It concentrates on sustainability and it tends to move from trying to define SD towards developing a concrete model for promoting and measuring sustainability achievements. The paper organizes sustainability assessment in terms of economic, environmental, and social performance. This structure has been chosen because it reflects what is currently the most widely accepted approach to defining sustainability (GRI, 2002). The main aim is to raise the quality of sustainability reporting to a higher level of consistency. The paper discusses how economic, environmental, and social indicators can be associated into sustainability sub-indices and finally into an overall indicator. This is applied by determining the impact of individual indicator to overall sustainability using the concept of analytic hierarchy process (AHP) (Saaty, 1980). The model uses normalized social, environmental, and economic indicators to incorporate them into a unique measure of performance.

Integrated information on sustainable development is very essential for decision-making since it is very difficult to evaluate the performance on the ground of too many indicators. The proposed model reduces the number of indicators by aggregating them into a composite sustainable development index (CSDI). The basic hierarchy of composing indicators into the CSDI is shown in Figure 5. ISO 31 was used as a guide to terms used in names and symbols for (physical) quantities (ISO, 1993).

The procedure of calculating the CSDI is divided into several parts, which are presented in Figure 6 (Krajnc and Glavic, 2005a) and Figure 7 (Krajnc and Glavic, 2005b). At first, the proper indicators are selected in the economic, environmental, and social group of indicators according to the main aspects of sustainability (economic, $j=1$; environmental, $j=2$; and social group of indicators, $j=3$ ) is determined. For each group $j$, indicators whose increasing value has a positive impact $\left(I_{\mathrm{A}}^{+}\right)$and indicators whose increasing value has a negative impact $\left(\Gamma_{\mathrm{A}}\right)$ in the perspective of sustainability are considered (see notation in Table 5 ).

Approximately 350 indicators (Petrosyan, 2010), which are classified into three dimensions, i.e. social, economic and environmental dimensions. Each dimension is subclassified into 6 themes (Figure 8). 
However, according to the availability of statistical data on the municipality of Neas Makris, the existing themes are as follows:

1) Social dimension is based on Population theme;

2) Economic dimension relies on Agriculture, Tourism, Agricultural Goods and Industry themes;

3) Environmental dimension represents the output of remote sensing data using Fragstat software.

Environmental Indicators are categorized into 6 themes, which has relationship to the environmental footprint presented by Eaton et al., (2007) and Chambers et al. (2000) (Figure 9). "Ecological" or environmental footprints (and related parameters) represent, albeit partial, sustainability indicators (Hammond, 2006).

The current paper outlines the evaluation of Biodiversity in Sustainable Development. The levels of biodiversity are shown in the following way (Figure 10), where evaluation of biodiversity using GIS as a tool are implemented. Recently the technology has been developed that even for Gene level some evaluations can be performed using Remote Sensing and Geographic Information System. However, here this case was preferably excluded in the current paper.

The general model for Biodiversity (Figure 10) and the proposed themes and indicators for sustainable development (Figure 8) have an interesting interlink, which is the following indication:

Ecosystem $=$ Dimensions $(\mathrm{S} ; \mathrm{EC} ; \mathrm{EN})$

Species $=$ Themes ( S1-S6; EC1-EC6; EN1-EN6)

Genes $\quad=$ Indicators organized by themes

Functions $=$ Interactions between Dimensions; Themes and Indicators

There is another interesting point to be mentioned in the current thesis. If Ecosystem is taken on the level of Themes, let say Agriculture (EC 4), then the following indication of the general model for biodiversity will be:

Ecosystem $=$ Agriculture $(\mathrm{EC} 4)$

Species = Agronomists; Lands; Plants; Trees; Animals; Water; Heats Pesticides etc.

Genes $\quad=$ Each agronomist with his own land, number of plants, trees and animals, the amount of used water, heat and pesticides

Functions $=$ Interactions between Ecosystem, Species and Genes to reach optimal needs and solutions

Finally, the concept of biodiversity presented like general model for biodiversity can be applied to different subjects and levels.

\subsubsection{Implementation}

The proposed model reduces the number of indicators by aggregating them into a composite sustainable development index (ICSD). The basic hierarchy of composing indicators into the ICSD is shown in Figure 7. The procedure of calculating the CSDI is divided into several parts: selecting, grouping, weighting, judging, normalizing indicators, calculating sub-indices and combining them into the CSDI. These procedural parts are presented in the following:

\section{A. Selecting Indicators}

Decision-makers have different views and are interested in different indicators. As indicators guide management control and strategic planning, Social, Economic and Environmental indicators have been applied to the Proposed Model with Dimensions, Themes and Indicators for Sustainable Development (Figure 8) according to the availability of statistical data (Table 4). However, according to the availability of statistical data on the municipality of Neas Makris, the existing themes are as follows:

1) Social dimension is based on Population theme;

2) Economic dimension relies on Agriculture, Tourism, Agricultural Goods and Industry themes;

3) Environmental dimension represents the output of remote sensing data using Fragstat software.

Due to not existence of Environmental Indicators the following attractive approach was offered for the retrieval of environmental indicators. In the paper of Petrosyan and Karathanassi (2010b), an attempt is made to investigate the usefulness of spatial techniques like Remote Sensing and GIS and to assess land use change and the related biodiversity variations. NDVI is calculated. Classification into 3 classes is performed. Landscape metrics using Fragstat software are computed (Petrosyan and Karathanassi, 2010a). The calculated metrics become an input to the model like Environmental Indicators. In addition, the concept of Biodiversity (Figure 10) are kept for Environmental Indicators in the following way:

Ecosystem $=$ Landscape Level

Species = Class Level

There are four classes, from which three are on Class Level, i.e. Class 1 is Sparse Vegetation, Class 2 is Medium Vegetation, Class 3 is Dense Vegetation, and the last one is on Landscape Level. 


\section{B. Grouping of Indicators}

Grouping of Indicators per theme and then each theme per dimension is shown in Table 1 and Figure 10. For the grouping the selected and existing indicators refer to the aforementioned point, i.e. Selecting Indicators.

\section{Weighting and judging indicators}

There are different strategies of SD, therefore different indicators attributing different weights to individual indicators are focused. Consequently, the next procedural part of calculating the CSDI involves determining weights, which should be combined with each indicator. Even more difficulties is expected in obtaining the weights for social indicators. Therefore, to derive the weights practically, the analytic hierarchy process (AHP) was used in the model.

The AHP (Saaty, 1980) has been accepted as a leading multi-attribute decision model, oth by practitioners and academics. In this paper it is tested to derive weights of indicators by the prioritization of their impact to overall sustainability assessment. Let us assume that $N$ indicators of SD are being considered with the goal of providing and quantifying judgments on the relative weight (expressed as fraction of importance) of each indicator with respect to all the other indicators of group $j$. The first step sets the problem as a hierarchy, where the topmost node is the overall objective of the decision, while subsequent nodes at lower levels consist of the criteria used in arriving at this decision.

The second step requires pair-wise comparisons to be made between each pair of indicators (of the given level of the hierarchy). This is done by pairwise comparisons between each pair of indicators, by giving to each indicator the values of 1 to 5, which shows the importance towards Sustainable Development. The comparisons are made by already posed determined value towards Sustainable Development how much the indicator i is more important than indicator $\mathrm{k}$ with respect to the $\mathrm{SD}$, respectively (Table 6). The value of 1 indicates equality between the two indicators while a preference of 5 indicates that one indicator is five times the importance of the one to which it is being compared. This scale was chosen, because in this way comparisons are being made within a limited range where perception is sensitive enough to make a distinction.

\section{Normalizing Indicators}

The main problem of aggregating indicators or data into the CSDI is the fact that indicators or data may be expressed in different units. One way to solve this problem could be normalizing each indicator $i$ by dividing its value in time (year) $t$ with its average value of all the time in years measured (Equations 1 and 2).

$$
I_{N, i j t}^{+}=\frac{I_{A, i j t}^{+}-I_{\min , j t}^{+}}{I_{\max , j t}^{+}-I_{\min , j t}^{+}} \quad I_{N, i j t}^{-}=\frac{I_{A, i j t}^{-}-I_{\min , j t}^{-}}{I_{\max , j t}^{-}-I_{\min , j t}^{-}}
$$

\section{E. Calculating the Sub-Indices}

The calculation of the CSDI is a step-by-step procedure of grouping various basic indicators into the sustainability sub-index $\left(\mathrm{I}_{\mathrm{S}, \mathrm{j}}\right)$ for each group of sustainability indicators $\mathrm{j}$. Sub-indices can be derived as shown in Equation 3.

\section{Equation 3: Calculating the Sub-Indices}

$$
\begin{aligned}
& I_{S, j t}=\sum_{j i t}^{n} W_{j i} \cdot I_{N, j i t}^{+}+\sum_{j i t}^{n} W_{j i} \cdot I_{N, j i t}^{-} \\
& \sum_{j i}^{n} W_{j i}=1, W_{j i} \geq 0
\end{aligned}
$$

where $I_{S, j t}$ is the sustainability sub-index for a group of indicators $j$ in time (year) $t . W_{j i}$ is the weight of indicator $\mathrm{i}$ for the group of sustainability indicators $\mathrm{j}$ and reflects the importance of this indicator in the sustainability assessment of the company.

\section{F. $\quad$ Combining the sub-indices into the CSDI}

Finally, the sustainability sub-indices are combined into the composite sustainable development index, CSDI (Equation 4).

Equation 6.4: Combining the sub-indices into the CSDI

$$
I_{C S D, t}=\sum_{j t}^{n} W_{j} \cdot I_{S, j t}
$$


where $\mathrm{W}_{\mathrm{j}}$ denotes the factor representing a priori weight given to the group $\mathrm{j}$ of SD indicators. These weights should reflect priorities in the opinion of the decision makers. In the final calculation of the CSDI, an approach that uses estimated weights can be considered. These weights reflect the importance given to the economic, environmental, and societal performance of the company.

\section{Results}

Social Sustainability Sub-index equals to the sum of Final Normalized Values of Social Dimensions and equals to the sum of Final Normalized Values of Population Theme (See Table 7).

Economic Sustainability Sub-index equals to the sum of Final Normalized Values of Economic Dimensions and equals to the sum of $1 / 4$ of Final Normalized Values of Each Theme. Lets perceive the sub-index each theme, which is presented on Table 8 .

Environmental Sustainability Sub-index equals to the sum of Final Normalized Values of Environmental Dimensions and equals to the sum of $1 / 4$ of Final Normalized Values of Each Theme. In present case, each theme represents type of vegetation on Class or Landscape Level. Lets perceive the sub-index each theme, which is presented on Table 9.

Sub-indices of each dimension, which are derived according to Equation 3, are presented in Table10. As a final point, Composite Sustainable Development Index is equal to $1 / 3$ of Social Sustainability Sub-Index $+1 / 3$ of Economic Sustainability Sub-Index $+1 / 3$ of Environmental Sustainability Sub-Index.

\section{Discussion}

Lets observe and make some conclusions on each sub-index or sub-sub indices.

Social Sustainability Sub-Index consists of mainly Population Sustainability Sub-Index. The graph on Figures 11 illustrates the variation of Social Sustainability Sub-Index.

As it is noticeable from Figure 11, the Social Sustainability Sub-Index reached the highest value in the year 1991, while in the years 1981 and 2001 it decreased. In other words there is an increase of the Social Sustainability Sub-Index for the period of 1981 to 1991 and there is a decrease of the Social Sustainability Sub-Index for the period of 1991 to 2001 .

Economic Sustainability Sub-Index consists of the four following Sustainability Sub-Indices: Agriculture, Tourism, Agricultural Goods and Industry. The graph on Figures 12 illustrates the Variation of Agriculture Sustainability Sub-Index. The graph on Figures 13 illustrates the Variation of Tourism Sustainability Sub-Index.

As it is obvious from Figure 12, the Agriculture Sustainability Sub-Index reached the highest value in the year 1981, while in the years 1991 and 2001 it decreased. In other words there is only a decrease of the Agricultural Sustainability Sub-Index for the period of 1981 to 1991 and for the periods of 1991 to 2001. This happens mainly because of the movement of population from villages to cities.

As it is observable from Figure 13, the Tourism Sustainability Sub-Index reached the highest value in the year 2001, while in the years 1981 and 1991 it decreased. In other words, there is only an increase of the Tourism Sustainability Sub-Index for the period of 1981 to 1991 and for the periods of 1991 to 2001. Even statistical data were collected after the year of 1993 that is why the value for the year of 1981 was given 0. Definitely, the Tourism Sustainability Sub-Index for the year of 1981 will be more than 0 but less than the value of the Tourism Sustainability Sub-Index for the year of 1991. This happens essentially because the tourism for Greece was given more attention after 1980s.

The graph on Figures 14 illustrates the Variation of Agricultural Goods Sustainability Sub-Index. The graph on Figures 15 illustrates the Variation of Industry Sustainability Sub-Index.

As it is visible from Figure 14, the Agricultural Goods Sustainability Sub-Index reached the highest value in the year 1991, while in the years 1981 and 2001 it decreased. In other words there is a decrease of the Agricultural Goods Sustainability Sub-Index for the periods of 1991 to 2001. Even statistical data were collected after the year of 1993 that is why the value for the year of 1981 was given 0. Definitely, the Agricultural Goods Sustainability Sub-Index for the year of 1981 will be even more the value of the Agricultural Goods Sustainability Sub-Index for the year of 1991. This conclusion is offered because of the movement of population from villages to cities.

As it is visible from Figure 15, the Industry Sustainability Sub-Index reached the highest value in the year 1991, while in the years 1981 and 2001 it decreased. In other words there is a decrease of the Industry Sustainability Sub-Index for the periods of 1991 to 2001. Even statistical data were collected after the year of 1993 that is why the value for the year of 1981 was given 0. Supposedly, the Industry Sustainability Sub-Index for the year of 1981 will be more than 0 but less than the value of the Industry Sustainability Sub-Index for the year of 1991. This conclusion is offered because of the movement of population from villages to cities. This happens essentially because the tourism for Greece was given more attention after 1980s and the Municipality of Neas Makris is a touristy place. 
Economic Sustainability Sub-Index consists of the four following Sustainability Sub-Indices: Agriculture (Figure 12), Tourism (Figure 13), Agricultural Goods (Figure 14) and Industry (Figure 15). The graph on Figures16 illustrates the variation of Economic Sustainability Sub-Index.

As it is conspicuous from Figure16, the Economic Sustainability Sub-Index reached the highest value in the year 1991, while in the years 1981 and 2001 it decreased. In other words there is an increase of the Economic Sustainability Sub-Index for the period of 1981 to 1991 and there is a decrease of the Economic Sustainability Sub-Index for the period of 1991 to 2001. Better conclusion could be derived in case of existence of statistical data for the year of 1981 .

Environmental Sustainability Sub-Index consists of the four following Sustainability Sub-Indices: Sparse, Medium and Dense Vegetation, Landscape. The graph on Figures 17 illustrates the Variation of Sparse Vegetation Sustainability Sub-Index. The graph on Figures 18 illustrates the Variation of Medium Sustainability Sub-Index.

As it is noticeable from Figure 17, the Sparse Vegetation Sustainability Sub-Index reached the highest value in the year 1991, while in the years 1981 and 2001 it decreased. In other words there is an increase of the Sparse Vegetation Sustainability Sub-Index for the period of 1981 to 1991 and there is a decrease of the Sparse Vegetation Sustainability Sub-Index for the period of 1991 to 2001.

As it is perceptible from Figure 18, the Medium Vegetation Sustainability Sub-Index reached the highest value in the year 1991, while in the years 1981 and 2001 it decreased. In other words there is an increase of the Medium Vegetation Sustainability Sub-Index for the period of 1981 to 1991 and there is a decrease of the Medium Vegetation Sustainability Sub-Index for the period of 1991 to 2001.

The graph on Figures 19 illustrates the Variation of Dense Vegetation Sustainability Sub-Index. The graph on Figures 20 illustrates the Variation of Landscape Sustainability Sub-Index.

As it is noticeable from Figure 19, the Dense Vegetation Sustainability Sub-Index reached the highest value in the year 1991, while in the years 1981 and 2001 it decreased. In other words there is an increase of the Dense Vegetation Sustainability Sub-Index for the period of 1981 to 1991 and there is a decrease of the Dense Vegetation Sustainability Sub-Index for the period of 1991 to 2001. It is even much more less the Dense Vegetation for the year of 2001. This happens, as due to increase of Tourists for the period of 1991 to 2001, there was more construction to enlarge the capability of Touristy places and the vegetation has been lost.

As it is perceptible from Figure 20, the Landscape Sustainability Sub-Index reached the highest value in the year 1991, while in the years 1981 and 2001 it decreased. In other words there is an increase of the Landscape Sustainability Sub-Index for the period of 1981 to 1991 and there is a decrease of the Landscape Sustainability Sub-Index for the period of 1991 to 2001. This happens, as due to increase of Tourists for the period of 1991 to 2001, there was more construction to enlarge the means of Touristy places and the vegetation at the Landscape level has been lost.

Environmental Sustainability Sub-Index consists of the four following Sustainability Sub-Indices: Sparse Vegetation (Figure 17), Medium Vegetation (Figure 18), Dense Vegetation (Figure 19) and Landscape (Figure 20). The graph on Figures 21 illustrates the variation of Environmental Sustainability Sub-Index.

As it is conspicuous from Figure 21, the Environmental Sustainability Sub-Index reached the highest value in the year 1991, while in the years 1981 and 2001 it decreased. In other words there is an increase of the Economic Sustainability Sub-Index for the period of 1981 to 1991 and there is a decrease of the Economic Sustainability Sub-Index for the period of 1991 to 2001. This happens, as due to increase of Tourists for the period of 1991 to 2001, there was more construction to enlarge the means of Touristy places and the vegetation at the both levels, i.e. Class and Landscape, has been vanished.

Composite Sustainable Development Index consists of the three following Sustainability Sub-Indices: Social (Figure 11), Economic (Figure 16), Environmental (Figure 21). The graph on Figures 22 illustrates the variation of Composite Sustainable Development Index.

As it is obvious from Figure 22, the Composite Sustainable Development Index reached the highest value in the year 1991, while in the years 1981 and 2001 it decreased. In other words there is an increase of the Composite Sustainable Development Index for the period of 1981 to 1991 and there is a decrease of the Composite Sustainable Development Index for the period of 1991 to 2001. This happens, due to increase of Social Sustainability Sub-Index; Economic Sustainability Sub-Index and Environmental Sustainability Sub-Index for the period of 1981 to 1991 and due to the decrease of Social Sustainability Sub-Index; Economic Sustainability Sub-Index and Environmental Sustainability Sub-Index for the period of 1991 to 2001.

\section{Conclusion}

The levels of biodiversity were shown in the following way (Figure 10), where not only economic and environmental evaluations were given but also evaluation of biodiversity using GIS as a tool. Later on it was concluded that the concept of biodiversity presented like general model for biodiversity was be applied to 
different subjects and levels. That is why the third dimension, i.e. Environmental Indicators, was more applied according to the concept of Biodiversity.

However, according to the availability of statistical data on the municipality of Neas Makris, the existing themes are as follows:

1) Social dimension is based on Population theme;

2) Economic dimension relies on Agriculture, Tourism, Agricultural Goods and Industry themes;

3) Environmental dimension represents the output of remote sensing data using Fragstat software.

An attractive approach is suggested for the environmental dimension. The calculated metrics become an input to the model like Environmental Indicators. In addition, the concept of Biodiversity are kept for Environmental Indicators in the following way: Ecosystem = Landscape Level and Species = Class Level.

Finally, the results, discussions and conclusions are provided for each existing theme, each dimension and composite sustainable development index.

\section{References}

Bell, S., Morse, S. (2004). Experiences with sustainability indicators and stakeholder participation: a case study relating to a 'Blue Plan' project in Malta. Sustainable Development 12(1): 1-14.

Blanc, I., Friot, D., Margni, M., Jolliet, O. (2008). Towards a new index for environmental sustainability based on a DALY weighting approach. Sustainable Development 16(4): 251-260.

Buchs, W. (2003). Biotic indicators for biodiversity and sustainable agriculture-introduction and background. Agriculture, Ecosystems \& Environment 98(1-3): 1-16.

Chambers, N., Wackernagel, M., Simmons, C. (2000). Sharing Natures Interest: Ecological Footprint as an indicator of sustainability. First ed. Earthscan.

Daly, H., Cobb, J. (1989). For the Common Good: Redirecting the Economy Towards Community, the Environment, and a Sustainable Future. Boston, MA, USA: Beacon Press.

De Kruijf, H.A.M., Van Vuuren, D. P. (1998). Following Sustainable Development in Relation to the North-South Dialogue: Ecosystem Health and Sustainability Indicators. Ecotoxicology and Environmental Safety 40 (1-2): 4-14.

Eaton, R.L., Hammond, G.P., Laurie, J. (2007). Footprints on the landscape: An environmental appraisal of urban and rural living in the developed world. Landscape and Urban Planning 83:13-28.

Edum-Fotwe, F.T., Price, A.D.F. (2009). A social ontology for appraising sustainability of construction projects and developments. International Journal of Project Management 27 (4): 313-322.

Ekins, P., Dresner, S., Dahlstrom, K. (2008). The four-capital method of sustainable development evaluation. European Environment 18(2): 63-80.

EUROSTAT. (2007). 2007 Review of the SDI set: List of Indicators Proposed by EUROSTAT. Fourth Meeting of the Working Grouo on Sustaianable Delopment Indicators. Meeting of 10-11 May 2007, Luxembourg, BECH Building Ampere Room.

Finco, A., Nijkamp, P. (2001). Pathways to urban sustainability. Journal of Environmental Policy and Planning 3(4): 289-302.

Gallopin, G. (1997). Indicators and their use: information for decision making. In: Moldan, B., Billharz, S. (Eds.), Sustainability Indicators. Report on the Project on Indicators of Sustainable Development. Wiley, Chicheste.

GRI - Global Reporting Initiative. (2002). Sustainability Reporting Guidelines 2002 on Economic, Environmental and Social Performance. Global Reporting Initiative, Boston, USA. Available at: http://www.globalreporting.org.

Hammond, G.P. (2006). "People, planet and prosperity": the determinants of humanity's environmental footprint. Natural Resource Forum 30: 27-36.

ISO - International Organization for Standardization. (1993). Quantities and Units, ISO Standards Handbook. Geneve.

JRC-Joint Research Center. (2002). Internal Market Index 2002: Technical Details of the Methodology. Institute for the Protection and Security of the Citizen, Technological and Economic Risk Management. Applied Statistics Group. Available at: http://www.jrc.cec.eu.int/.

Keirstead, J., Leach, M. (2008). Bridging the gaps between theory and practice: a service niche approach to urban sustainability indicators. Sustainable Development 16(5): 329-340.

Kosioni-Koen, M., Papastergiou-Mitsopoulou, E. (2004). General scheme for the urban-planning: The Municipality of Neas Makris. Prefectional Self-Administration of East Athens. 
Krajnc, D., Glavic, P. (2005a). A model for integrated assessment of sustainable development. Resources, Conservation and Recycling 43: 189-208.

Krajnc, D., Glavic, P. (2005b). How to compare companies on relevant dimensions of sustainability. Ecological Economics 55: 551-563.

Ledoux, L., Mertens, R., Wolff, P. (2005). EU sustainable development indicators: An overview. Natural Resources Forum 29(4): 392-403.

Levett, R. (1998). Sustainability indicators-integrating quality of life and environmental protection. Journal of the Royal Statistical Society: Series A (Statistics in Society) 161(3): 291-302.

Lyytimaki, J., Rosenstrom, U. (2008). Skeletons out of the closet: effectiveness of conceptual frameworks for communicating sustainable development indicators. Sustainable Development 16(5): 301-313.

Murray, C.J.L., Lauer, J., Tandon, A., Frenk, J. (2001). Overall health system achievement for 191 countries. Global Programme on Evidence for Health Policy Discussion Paper Series: No. 28. World Health Organization (WHO). Available at: http://www3.who.int/whosis/discussion papers/pdf/paper28.pdf

OECD - Organization for Economic Co-operation and Development. (2002). An Update of the OECD Composite Leading Indicators. Short-term Economic Statistics Division, Statistics Directorate/OECD. Available at: http://www.oecd.org.

OECD - Organization for Economic Cooperation and Development. (1993). OECD core set of indicators for environmental performance reviews. OECD Environment Monographs 83. Paris, France.

O’Regan, B., Morrissey, J., Foley, W., Moles, R. (2009). The relationship between settlement population size and sustainable development measured by two sustainability metrics. Environmental Impact Assessment Review 29: 169-178.

Pagina, W. (2000). Measurement and indicators for sustainable development. Manitoba: International Institute for Sustainable Development.

Patlitzianas, K.D., Doukas, H., Kagiannas, A.G., Psarras, J. (2008). Sustainable energy policy indicators: Review and recommendations. Renewable Energy 33(5): 966-973.

Petrosyan, A. (in Progress). Evaluation of the biodiversity in Sustainable Development using GIS. PhD thesis in National Technical University of Athes, Greece.

Petrosyan, A., Karathanassi, V. (2010a). Review Article of Landscape Metrics based on Remote Sensing Data. Geocarto (In Process).

Petrosyan, A., Karathanassi, V. (2010b). Landscape evaluation using remotely-sensed data. International Journal of Applied Earth Observation and Geoinformation (In Process).

Pre Consultants. (2001). The Eco-indicator 99 - a damage oriented method for life cycle impact assessment. Methodology Report. Available at: http://www.pre.nl/.

Ravetz, J. (2000). Integrated assessment for sustainability appraisal in cities and regions. Environmental Impact Assessment Review 20(1): 31-64.

Rigby, D., Woodhouse, P., Young, T., Burton, M. (2001). Constructing a farm level indicator of sustainable agricultural practice. Ecological Economics 39(3): 463-478.

Saaty, T.L. (1980). Analytical Hierarchy Process: Planning, Priority Setting, Resource Allocation. NewYork: McGraw-Hill.

Sartorius, C. (2006). Second-order sustainability - conditions for the development of sustainable innovations in a dynamic environment. Ecological Economics 58(2): 268-286.

Simianer, H. (2005). Decision making in livestock conservation. Ecological Economics 53: 559- 572.

Singh, R.K., Murty, H.R., Gupta, S.K., Dikshit, A.K. (2009). An overview of sustainability assessment methodologies. Ecological Indicators 9: 189 - 212.

Spangenberg, J.H., Lorek, S. (2002). Environmentally sustainable household consumption: from aggregate environmental pressures to priority fields of action. Ecological Economics 43(2-3): 127-140.

Spangenberg, J.H, Pfahl, S., Deller, K. (2002). Towards indicators for institutional sustainability: lessons from an analysis of Agenda 21. Ecological Indicators 2(1-2): 61-77.

Statistics Finland. (2003). Index of Environmental Friendliness. Available at: http://www.stat.fi/tk/yr/ye22 en.html.

Tate, J. (2002). Void dwellings - a "headline" indicator? Sustainable Development 10(1): 36-50.

The Energy \& Biodiversity Initiative. (2002). Biodiversity Indicators for Monitoring Impacts and Conservation Actions. 
UNDP - United Nations Development Programme. (1990-2003). Human Development Report. New York: Oxford University Press. Available at: http://hdr.undp.org/

Varma, V.K., Ferguson, I., Wild, I. (2000). Decision support system for the sustainable forest management. Forest Ecology and Management 128 (1-2): 49-55.

WEF-World Economic Forum's Global Leaders for Tomorrow Environment Task Force, YCELP-Yale Center for Environmental Law and Policy, and CIESIN-the Columbia University Center for International Earth Science Information Network. (2002). The Environmental Sustainability Index (ESI). New Haven, CT.

Wilson, J., Tyedmers, P., Pelot, R. (2007). Contrasting and comparing sustainable development indicator metrics. Ecological Indicators 7: 299-314.

Yuan, W., and James, P. (2002). Evolution of the Shanghai city region 1978-1998: an analysis of indicators. Journal of Environmental Management 64: 299-309.

Table 1. Three dimension of SD with proposed sub-classified 6 themes

\begin{tabular}{|l|l|l|}
\hline 1. Social (S): & 2. Economic (EC) : & 3. Environmental (EN) : \\
S1 : Population; & EC1 : Investment; & EN1 : Land \& Soil; \\
S2 : Social Conditions; & EC2 : Standart of Living; & EN2 : Water ; \\
S3 : Knowledge \& Wisdom; & EC3 : Production \& Consumption; & EN3 : Air ; \\
S4 : Physical \& Psychological Health; & EC4 : Agriculture; & EN4 : Biodiversity ; \\
S5 : Political Conditions; & EC5 : Industry; & EN5 : Climate Change \& Energy ; \\
S6 : Transport. & EC6 : Tourism. & EN6 : Nature.
\end{tabular}

Table 2. Available Remote Sensing Data

\begin{tabular}{|l|l|l|c|}
\hline No. & Type of data used & Resolution & Acquisition Date \\
\hline $\mathbf{1 .}$ & Landsat $\boldsymbol{T M}$ image & $\mathbf{3 0 m}$ & $\mathbf{2 3 / 1 0 / 1 9 8 4}$ \\
\hline 2. & Landsat TM image & $30 \mathrm{~m}$ & $13 / 08 / 1987$ \\
\hline 3. & Landsat $\boldsymbol{T M}$ image & $\mathbf{3 0 m}$ & $\mathbf{0 4} / \mathbf{0 7 / 1 9 9 0}$ \\
\hline 4. & Landsat TM image & $30 \mathrm{~m}$ & $14 / 09 / 1993$ \\
\hline 5. & Landsat TM image & $30 \mathrm{~m}$ & $14 / 08 / 1996$ \\
\hline 6. & Landsat ETM+ image & $30 \mathrm{~m}$ & $05 / 07 / 1999$ \\
\hline 7. & Landsat ETM+ image & $\mathbf{3 0 m}$ & $\mathbf{1 4} / \mathbf{0 8} / \mathbf{2 0 0 2}$ \\
\hline
\end{tabular}

Table 3. Available Statistical Data

\begin{tabular}{|l|l|c|}
\hline No. & Description & Dates \\
\hline 1. & Population & $1981,1991,2001$ \\
\hline 2. & Agriculture & $1981,1991,2001$ \\
\hline 3. & Tourism & $1993-2007$ \\
\hline 4. & Agricultural Goods & $1993-2006$ \\
\hline 5. & Industry & $1993-2008$ \\
\hline
\end{tabular}

Table 4. Suggested Statistical Data

\begin{tabular}{|l|l|c|c|c|}
\hline No. & Description & Date 1 & Date 2 & Date 3 \\
\hline 1. & Population & 1981 & 1991 & 2001 \\
\hline 2. & Agriculture & 1981 & 1991 & 2001 \\
\hline 3. & Tourism & - & 1993 & 2001 \\
\hline 4. & Agricultural Goods & - & 1993 & 2001 \\
\hline 5. & Industry & - & 1993 & 2001 \\
\hline
\end{tabular}


Table 5. Notation used in the definition of sustainability indicators

\begin{tabular}{|c|c|c|c|}
\hline Group of indicators & Group notation, $j$ & $\begin{array}{c}\text { Indicators with positive } \\
\text { impact }\end{array}$ & $\begin{array}{c}\text { Indicators with } \\
\text { negative impact }\end{array}$ \\
\hline Economic group & 1 & $\Gamma_{\mathrm{A}, 1 i}^{+} i=1, \ldots, n$ & $\Gamma_{A, 1 i} i=1, \ldots, n$ \\
\hline Environmental group & 2 & $\Gamma_{\mathrm{A}, 2 i} i=1, \ldots, n$ & $\Gamma_{A, 2 i} i=1, \ldots, n$ \\
\hline Environmental group & 3 & $\Gamma_{\mathrm{A}, 3 i} i=1, \ldots, n$ & $\Gamma_{A, 3 i} i=1, \ldots, n$ \\
\hline
\end{tabular}

Table 6. Importance towards Sustainable Development

\begin{tabular}{|l|l|}
\hline Factor of Preference & Importance Definition \\
\hline 1 & Less Importance \\
\hline 2 & Moderate Importance \\
\hline 3 & Strong or essential importance \\
\hline 4 & Very strong or demonstrated importance \\
\hline 5 & Extreme importance of one over another \\
\hline
\end{tabular}

Table 7. Social Sustainability Sub-Index

\begin{tabular}{|c|c|c|c|}
\hline & 1981 & 1991 & 2001 \\
\hline Population Sustainability Sub-Index & 0.01354 & 0.01493 & 0.01374 \\
\hline Social Sustainability Sub-Index & 0.01354 & 0.01493 & 0.01374 \\
\hline
\end{tabular}

Table 8. Economic Sustainability Sub-Index

\begin{tabular}{|c|c|c|c|}
\hline & 1981 & 1991 & 2001 \\
\hline Agriculture Sustainability Sub-Index & 0.13659 & 0.12309 & 0.08879 \\
\hline Tourism Sustainability Sub-Index & - & 0.02893 & 0.05674 \\
\hline Agricultural Goods Sustainability Sub-Index & - & 0.03635 & 0.03309 \\
\hline Industry Sustainability Sub-Index & - & 0.08902 & 0.07796 \\
\hline Economic Sustainability Sub-Index & 0.03415 & 0.06935 & 0.06415 \\
\hline
\end{tabular}

Table 9. Environmental Sustainability Sub-Index

\begin{tabular}{|c|c|c|c|}
\hline & 1981 & 1991 & 2001 \\
\hline Sparse Vegetation Sustainability Sub-Index & 0.01404 & 0.02051 & 0.01583 \\
\hline Medium Vegetation Sustainability Sub-Index & 0.01555 & 0.01572 & 0.01548 \\
\hline Dense Vegetation Sustainability Sub-Index & 0.01588 & 0.01917 & 0.01022 \\
\hline Landscape Sustainability Sub-Index & 0.01535 & 0.01588 & 0.01547 \\
\hline Environmental Sustainability Sub-Index & 0.01520 & 0.01782 & 0.01425 \\
\hline
\end{tabular}

Table 10. Results of Sustainability Sub-Indices per Dimension and Composite Sustainable Development Index

\begin{tabular}{|c|c|c|c|}
\hline & 1981 & 1991 & 2001 \\
\hline Social Sustainability Sub-Index & 0.01354 & 0.01493 & 0.01374 \\
\hline Economic Sustainability Sub-Index & 0.03415 & 0.06935 & 0.06415 \\
\hline Environmental Sustainability Sub-Index & 0.01520 & 0.01782 & 0.01425 \\
\hline Composite Sustainable Development Index & 0.02096 & 0.03403 & 0.03071 \\
\hline
\end{tabular}




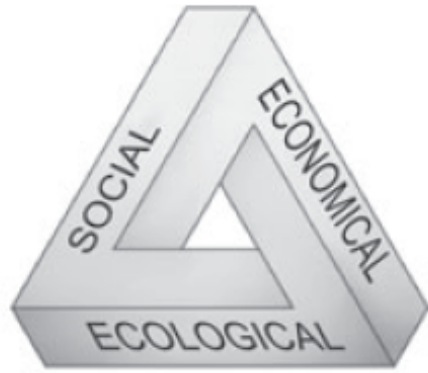

Figure 1. Holistic illustration of sustainable development framework

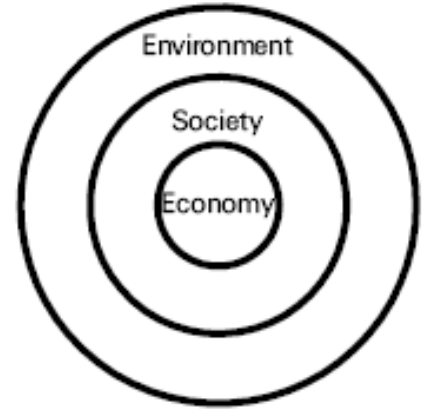

Figure 2. (Proposed) Russian dolls model of sustainability.

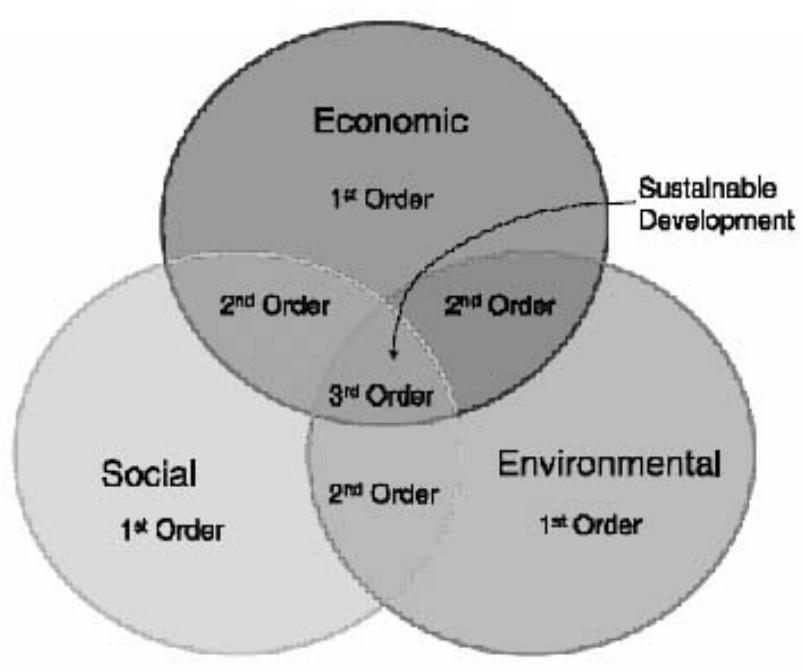

Figure 3. Underlying concept of sustainable development in SUE-MoT
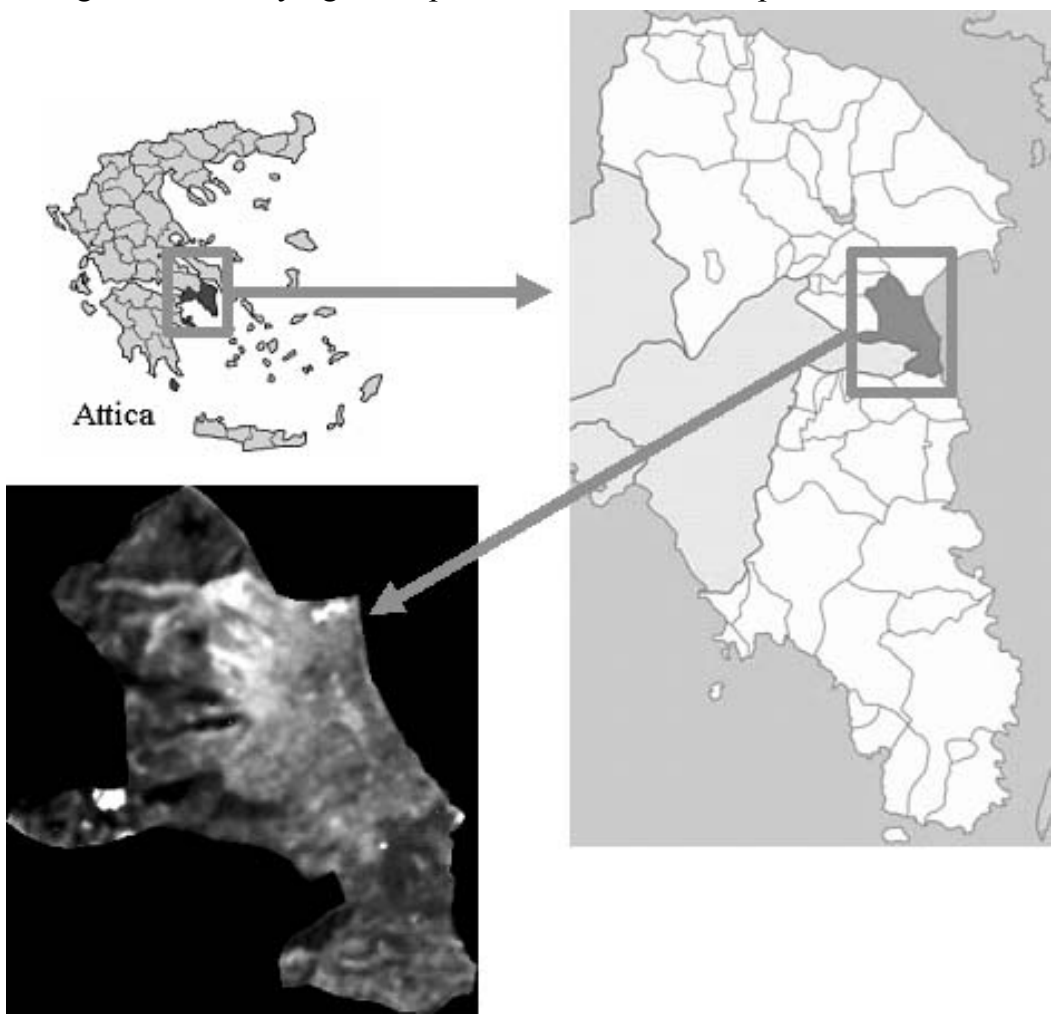

Figure 4. Municipality of Neas Makris, Attica, Greece 


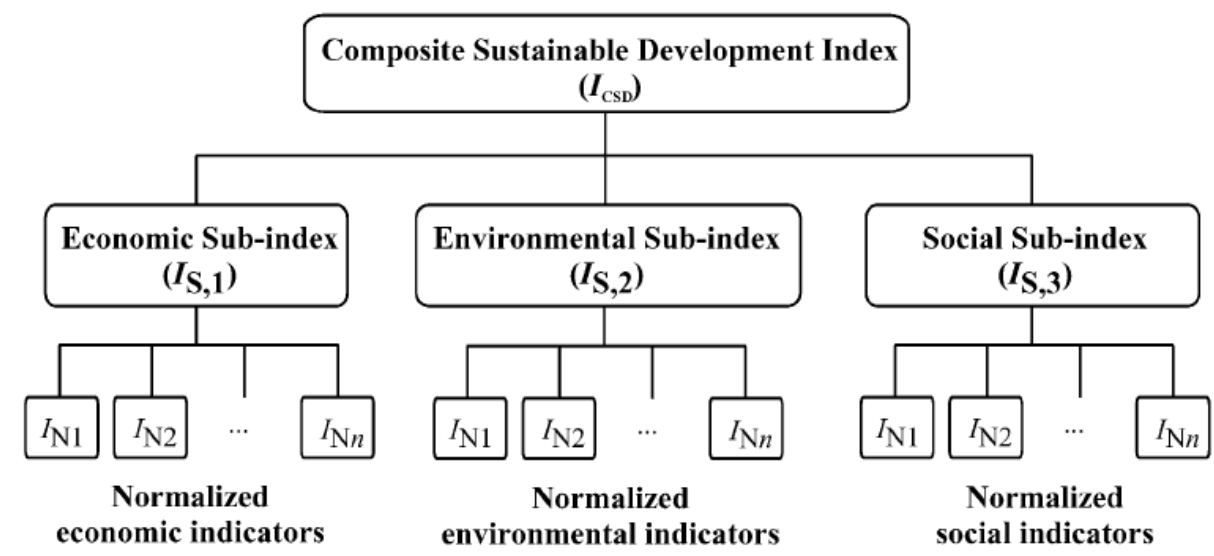

Figure 5. Generic hierarchy scheme for calculation of composite sustainable development index

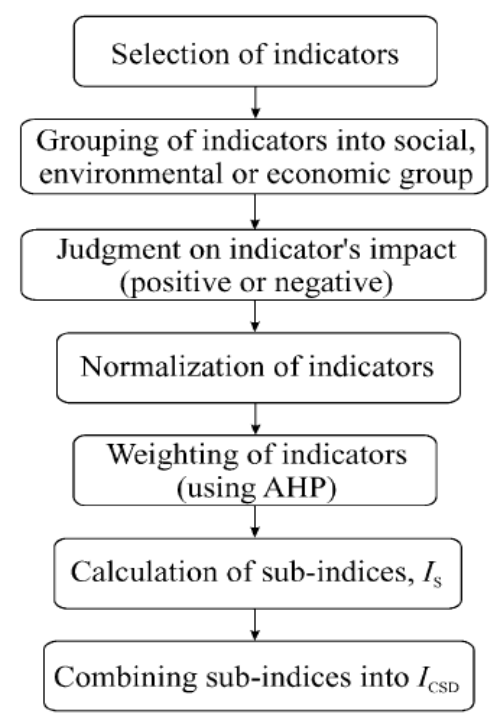

Figure 6. The procedure of calculating the CSDI

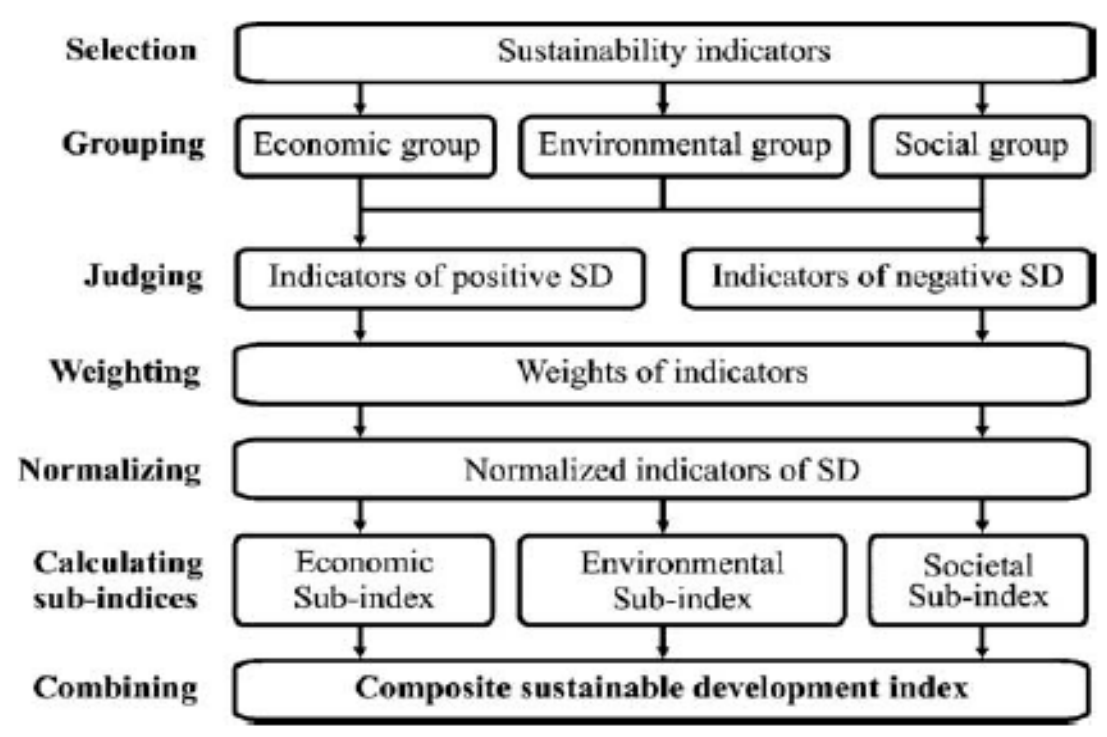

Figure 7. Scheme for calculation of composite sustainable development index 


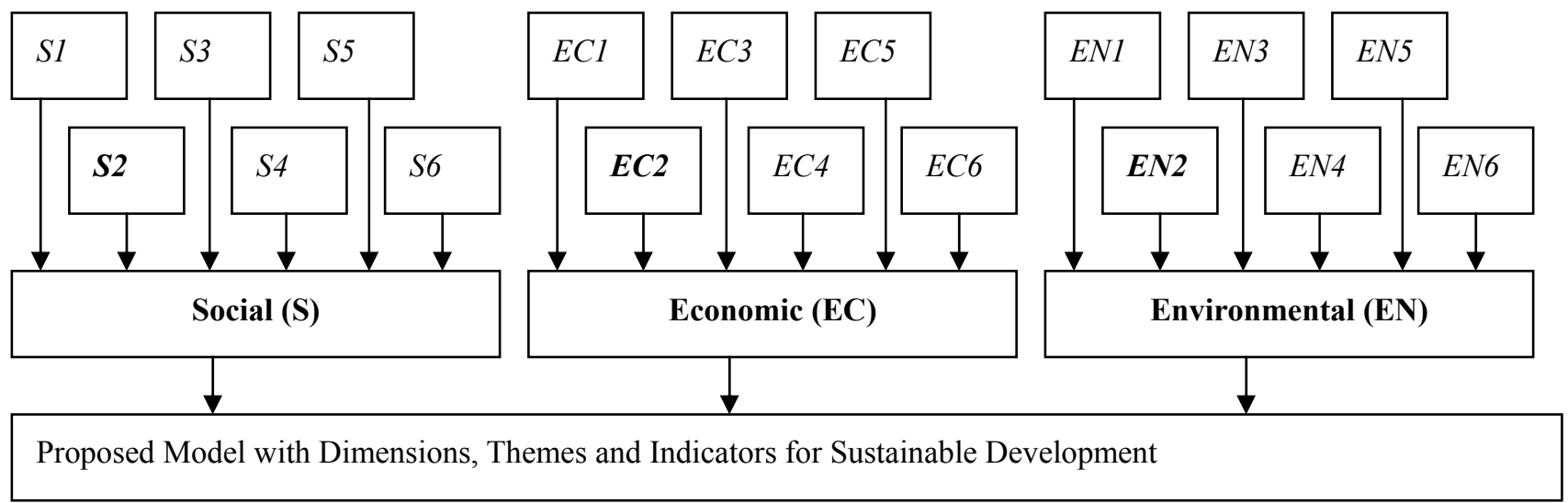

\section{Social (S) :}

S1 : Population;

S2 : Social Conditions;

S3 : Knowledge \& Wisdom;

S4 : Physical \& Psychological

Health;

S5 : Political Conditions;

S6 : Transport.
2. Economic (EC) :
EC1 : Investment;
EC2 : Standart of Living;
EC3 : Production \&
Consumption;
EC4 : Agriculture;
EC5 : Industry;
EC6 : Tourism.

3. Environmental (EN) :

EN1 : Land \& Soil;

EN2 : Water ;

EN3 : Air ;

EN4 : Biodiversity ;

EN5 : Climate Change \& Energy ;

EN6 : Nature.

Figure 8. Proposed Model with Dimensions, Themes and Indicators for Sustainable Development

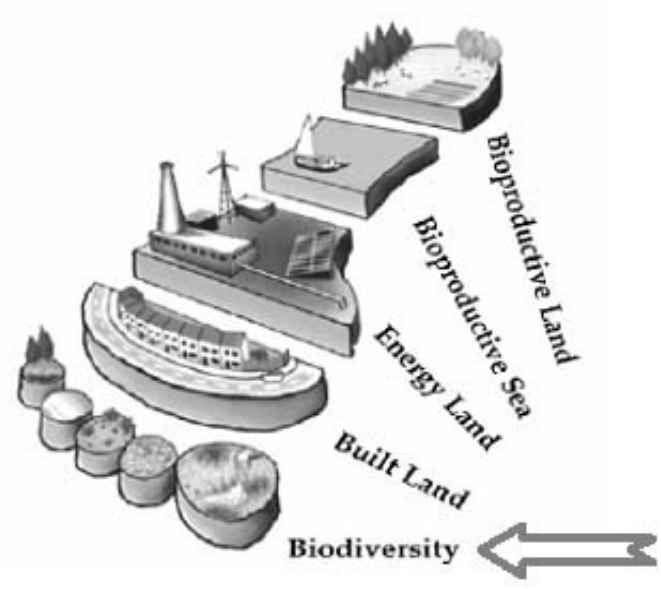

Figure 9. Schematic Representation of the Environmental Footprint, and its Land Types

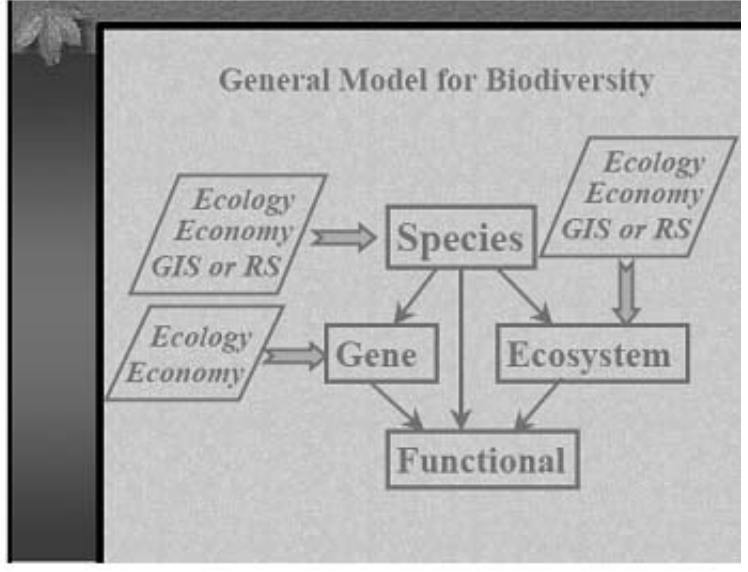

Figure 10. General Model for Biodiversity 

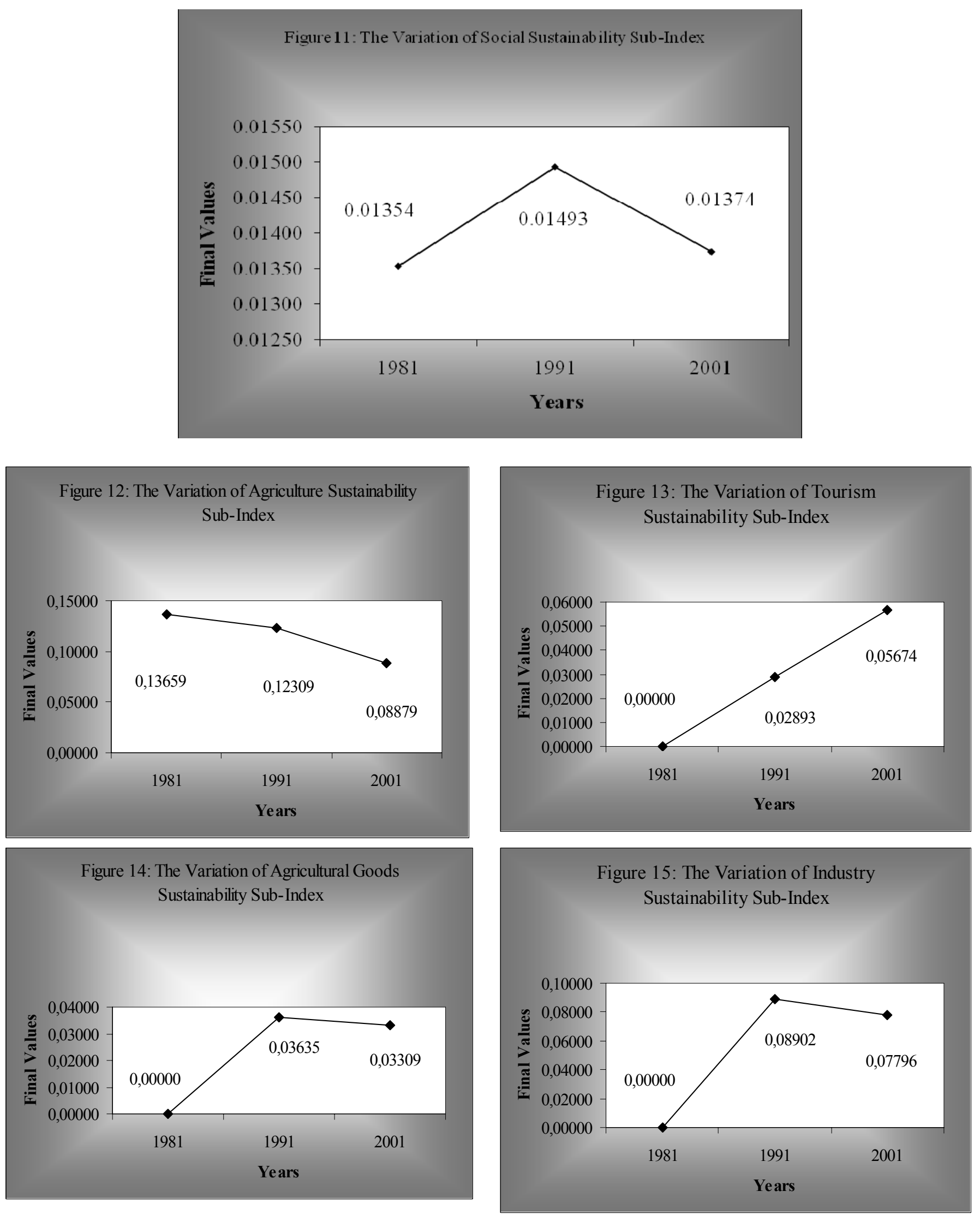

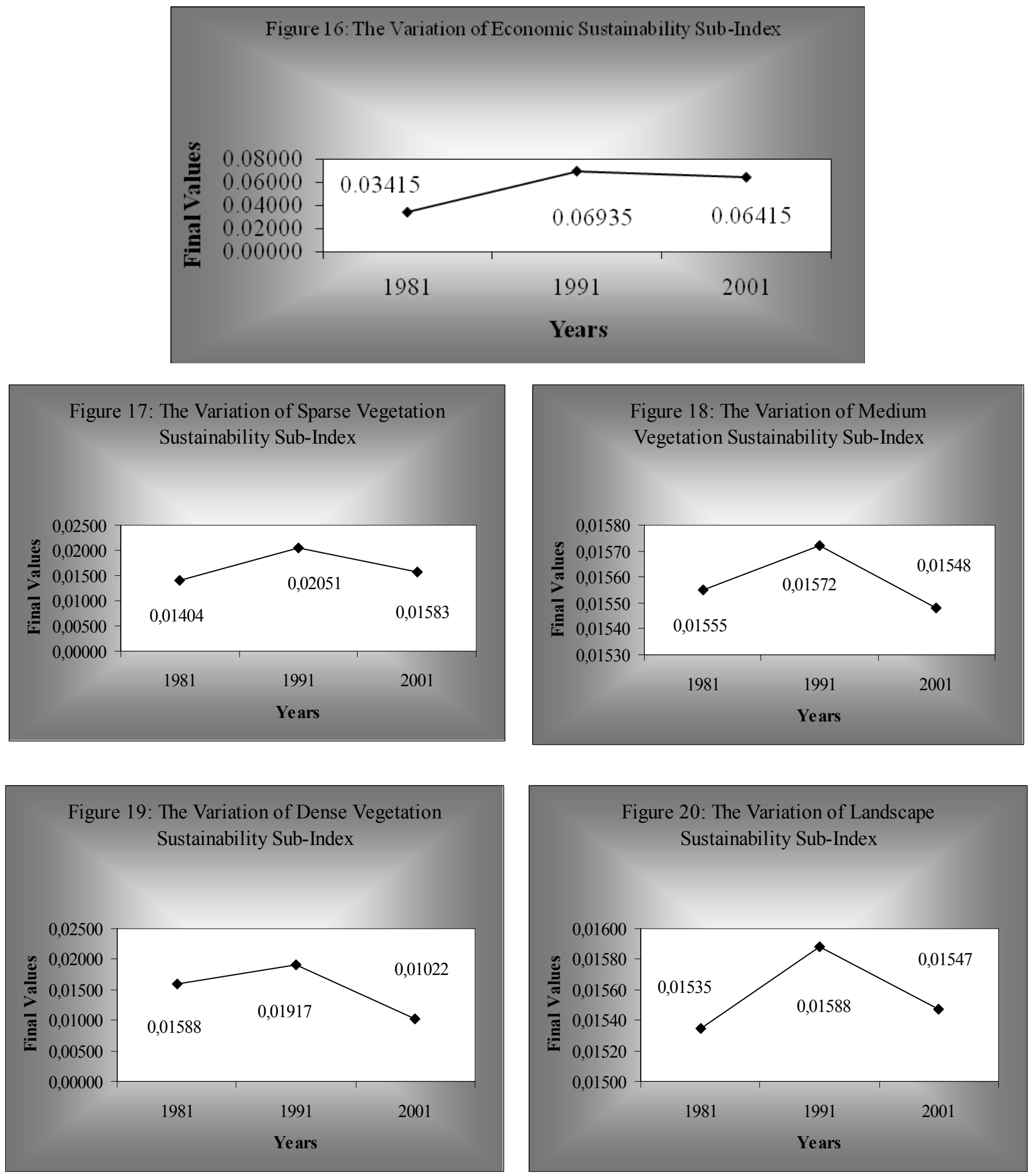

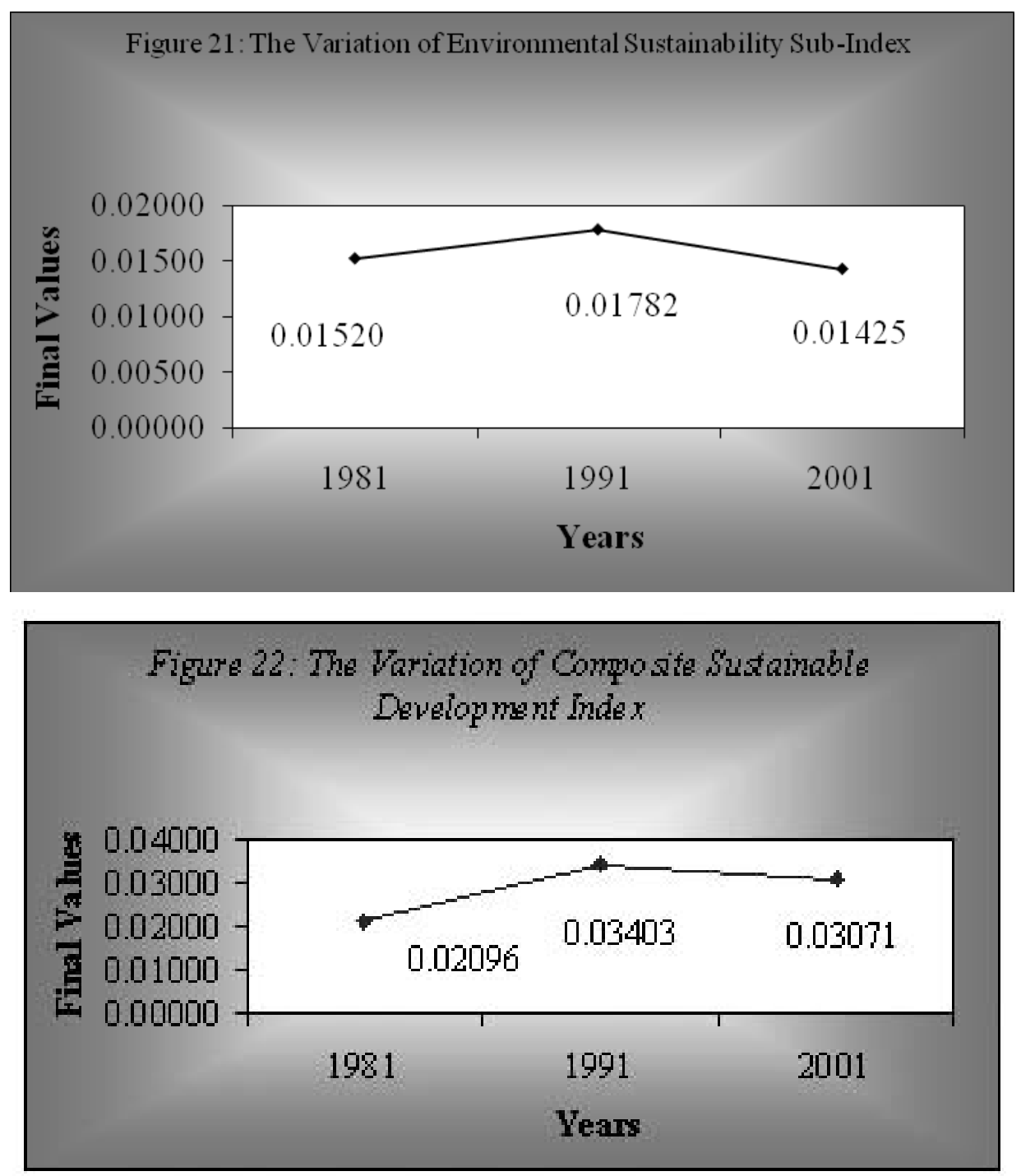